\title{
ANÁLISE DAS REFLEXÕES DA PROFESSORA DE CIÊNCIAS SOBRE A SUA RELAC̣̃̃O COM OS ALUNOS E IMPLICAC̣ÕES PARA A PRÁTICA EDUCATIVA
}

\author{
Patrícia de Oliveira Rosa-Silva* \\ Álvaro Lorencini Júnior* * \\ Carlos Eduardo Laburú ${ }^{* *}$
}

RESUMO: Neste trabalho enfocamos as reflexões de dimensão discente de uma professora de Ciências. Para a coleta de dados, realizamos uma parceria colaborativa entre a pesquisadora e a professora, durante as horas/atividade na escola. Utilizamos a autoscopia trifásica como estratégia de formação continuada, que possibilitou à professora refletir sobre a prática nas fases pré-ativa e pós-ativa, ou seja, antes e depois de ela ter desenvolvido as aulas (fase interativa). Apresentamos os dados da fase pós-ativa analisados à luz do referencial teórico sobre o conceito de prática reflexiva, segundo Schön $(1997,2000)$. As reflexões da professora demonstram que ela buscou avaliar a prática educativa mediante questionamentos, proposição de soluções e reestruturação de ações que a levariam a dissolver os preconceitos que criou contra os alunos para melhorar sua ação docente.

Palavras-chave: Ensino de Ciências. Formação Continuada na Escola. Reflexão sobre a Prática.

\section{ANALYSIS OF THE SCIENCE TEACHER'S REFLECTIONS ABOUT HER RELATIONSHIP WITH THE STUDENTS AND IMPLICATIONS ON THE EDUCATIONAL PRACTICE}

ABSTRACT: In this work, we focus on the students dimension reflections of a Science teacher. For the data collection, a partnership between the researcher and the teacher was established, along with the school activity hours. We have used the triphasic autoscopy as a strategy for the educational development, which allowed the teacher to reflect on the pre-active and post-active phases, i.e., after and before she taught the classes (interactive phase). We presented the post-active data analyzed under the light of the theoretical reference on the reflexive practice concept, according to Schön $(1997,2000)$. The teacher's reflections showed that she tried to evaluate the educational practice by means of inquiring, proposition of solutions and action restructuring, which led her overcome the prejudices she had against the students thus improving her teaching practices.

Keywords: Science Teaching. Higher Education. Reflection upon Practices. 


\section{INTRODUÇÃO}

O ensino e a aprendizagem dependem, cada vez mais, de professores comprometidos em melhorar a sua atuação em sala de aula. Um dos meios para se desenvolver essa melhoria é pela reflexão sobre a experiência educativa do professor (DEWEY, 1979).

Nóvoa (2001) afirma que a reflexão sobre a prática está diretamente relacionada à natureza do trabalho docente. Para este autor, a complexidade de ser professor hoje é maior do que era há 50, 60 ou 70 anos, pelo fato de a "escola para todos" enumerar inúmeros desafios, dentre eles o de oferecer ensino com qualidade satisfatória a todos os alunos que frequentam a sala de aula: estudantes de todas as classes sociais, de todas as etnias e de todos os grupos econômicos - desde os mais pobres até os mais ricos. Diante disso, mudar o ensino é um imperativo e refletir sobre as condicionantes que permeiam a natureza da ação docente é fundamental para o professor tomar decisões e resolver situaçõesproblemas, nas quais se destacam as zonas indeterminadas da prática, constituídas pelos conflitos, pela singularidade e pela incerteza das situações educativas que emergem da própria prática (SCHÖN, 2000).

A reflexão docente, contudo, não se cumpre pelo simples fato de o profissional estar na escola. São necessários grupos de professores dedicados à discussão dos temas da prática, ao estudo sistematizado e à resolução de problemas/dificuldades, sendo imprescindível o trabalho de assessoria pedagógica nesse processo (CANDAU, 1997). Partindo desse pressuposto de formação continuada adicionamos a concepção de Elliot (1998), que considera o pesquisador como promotor do desenvolvimento do professor em uma perspectiva discursiva e reflexiva da sua própria prática, para estabelecermos uma parceria colaborativa com uma professora de Ciências na escola.

Este estudo tem como objetivo analisar as reflexões que a professora fez sobre os alunos, as quais tiveram influência significativa sobre a prática educativa, como veremos mais adiante. As reflexões analisadas foram externadas pela professora nos momentos de reflexão sobre a ação, ou seja, após ela ter preparado e desenvolvido as aulas, demonstrando, assim, o processo pelo qual as reflexões indicaram mudanças na sua relação com os alunos.

\section{0 CONCEITO DE PRÁTICA REFLEXIVA}

A formação continuada de professores na dimensão reflexiva tornouse uma constante, a partir da década de 1980, com o conceito de prática reflexiva proposto por Schön. Este autor defende uma formação docente baseada em uma epistemologia da prática, na qual o professor pode lançar mão da sua experiência educativa, valorizando-a no contexto social, por meio da reflexão e do conhecimento tácito (SCHÖN, 2000). 
Schön sustenta o conceito de reflexão de Dewey (1979, p. 13): “espécie de pensamento que consiste em examinar mentalmente o assunto e dar-lhe consideração séria e consecutiva". Para Dewey (1979), consecutividade significa sequência de pensamentos concentrados em um objeto de análise, com flexibilidade, variedade e mudanças de posições de ideias, mas sem que haja desvio do objetivo a alcançar.

O conhecimento na ação é um conhecimento tácito, prático, interiorizado e implícito (POLANYI apud SCHÖN, 2000), que não precede à ação, mas é indissociável da própria ação. Nesse enfoque, a atividade do professor se desenvolve em um contexto complexo, onde a habilidade de resolver problemas práticos depende de uma "conversação reflexiva" com a prática e a situação problemática. Não há uma separação entre pensar e fazer, já que ambas as ações estão entrelaçadas num "diálogo" que se origina na ação prática com o contexto social em que estão inseridas (LORENCINI JÚNIOR, 2009).

Esse conhecimento é, porém, insuficiente para solucionar os problemas que ocorrem na prática. Assim sendo, Schön (1997, 2000) recomenda que o professor observe atentamente a sala de aula, que é considerada heterogênea, conflituosa e incerta, e mobilize o seu conbecimento tácito por meio da reflexão sobre a prática. $\mathrm{O}$ autor defende três processos reflexivos que podem auxiliar o professor na sua atividade docente: a reflexão na ação, a reflexão sobre a ação e a reflexão sobre a reflexão-na-ação.

A reflexão na ação é "um processo de conhecer-na-ação que pode ser descrito em termos de estratégias, compreensão de fenômenos e formas de conceber uma tarefa ou problema adequado à situação" (SCHÖN, 2000, p. 33). Nessa reflexão, o conhecimento tácito orienta a atividade prática sem conferirlhe uma sistematização, mas uma espontaneidade e criatividade para responder as múltiplas variáveis que atuam no contexto. Quando o professor se mostra aberto às interações complexas do exercício docente, a reflexão na ação é uma atividade de construção de significados sobre a prática, pois acontece um processo de aprendizagem em que o professor interage com a situação ao mesmo tempo em que está refletindo (LORENCINI JÚNIOR, 2009). O professor ocupado em examinar uma situação particular, observa-a escolhendo e nomeando aspectos para solucionar o caso na ação, por meio de uma sequência espiralada de estágios reflexivos, a saber:

Alerta: ocorre quando o professor está curioso ou intrigado com algum aspecto do cenário da sua prática. No calor da ação, o aluno apresenta diferentes tipos de respostas a uma situação de ensino e o professor surpreendese pelo que o aluno faz (SCHÖN, 1997).

Estruturação: ocorre quando o professor, por meio da reflexão descritiva, expõe o problema de forma explícita, específica e exterioriza um tipo de inteligência tácita. Nesse ponto, o professor tem um modo de apreender, representar e enquadrar os fenômenos em sistemas de referências cognitivas e valorativas/apreciativas que o levam a prestar atenção a certos aspectos da 
situação e não a outros (ALARCÃO, 2000). Em outras palavras, o professor interpreta o caso relacionando-o às particularidades do cenário da prática e de acordo com as teorias e modelos pedagógicos que lhe embasam. Na estruturação, o docente procura compreender o motivo pelo qual foi surpreendido, pensando sobre as ações discente e docente (SCHÖN, 1997).

Reestruturação: ocorre quando o professor reinterpreta determinado aspecto do problema à luz da experiência prévia. Neste estágio, ele reflete criticamente sobre a situação para entender seus próprios pontos de vista, os dos alunos ou os de outras pessoas na tentativa de solucionar o problema suscitado pela situação (CLARKE, 1994). O professor levanta hipóteses de ensino para reestruturar as compreensões dos fenômenos, a forma de entender os problemas e as estratégias de ação. Segundo Schön (2000), isso só é possível quando o professor questiona e põe em conflito os pressupostos do conhecimento tácito.

Plano de ação: ocorre quando o professor, utilizando-se de novos pontos de referência e interpretações, experimenta novas ações para explorar os fenômenos recém-observados, buscando compreendê-los com os objetivos de afirmar e melhorar as ações que criou. Nessa situação, o professor, ocupado em examinar a hipótese que formulou sobre o modo de pensar do aluno, por exemplo, propõe uma ação pedagógica para averiguar tal hipótese e, assim, reconsiderar as proposições que criou para futuras tomadas de decisões (SCHÖN, 1997).

Schön (2000) admite que esses estágios reflexivos não são tão distintos na ação e nem sempre ocorrem nessa sequência. $O$ professor pode focar a atenção em uma situação educativa para interpretá-la ou, então, a situação que ele enfrenta já foi vivenciada de forma similar e ele pode reconsiderá-la para novas interpretações, como ele pode também, por meio da reinterpretação da circunstância educativa, ser novamente alertado, criticando e remodelando o ato de conhecer na ação para experimentar novas ações educativas para solucionar o problema suscitado. A reflexão na ação é um processo que não exige o uso de palavras para explicar o que o profissional está fazendo, mas implica reconduzir ações adequadas de ensino e "sua imediata significação para a ação" (SCHÖN, 2000, p, 34). reflexiva.

A Figura 1 mostra o esquema que Schön denomina de prática 


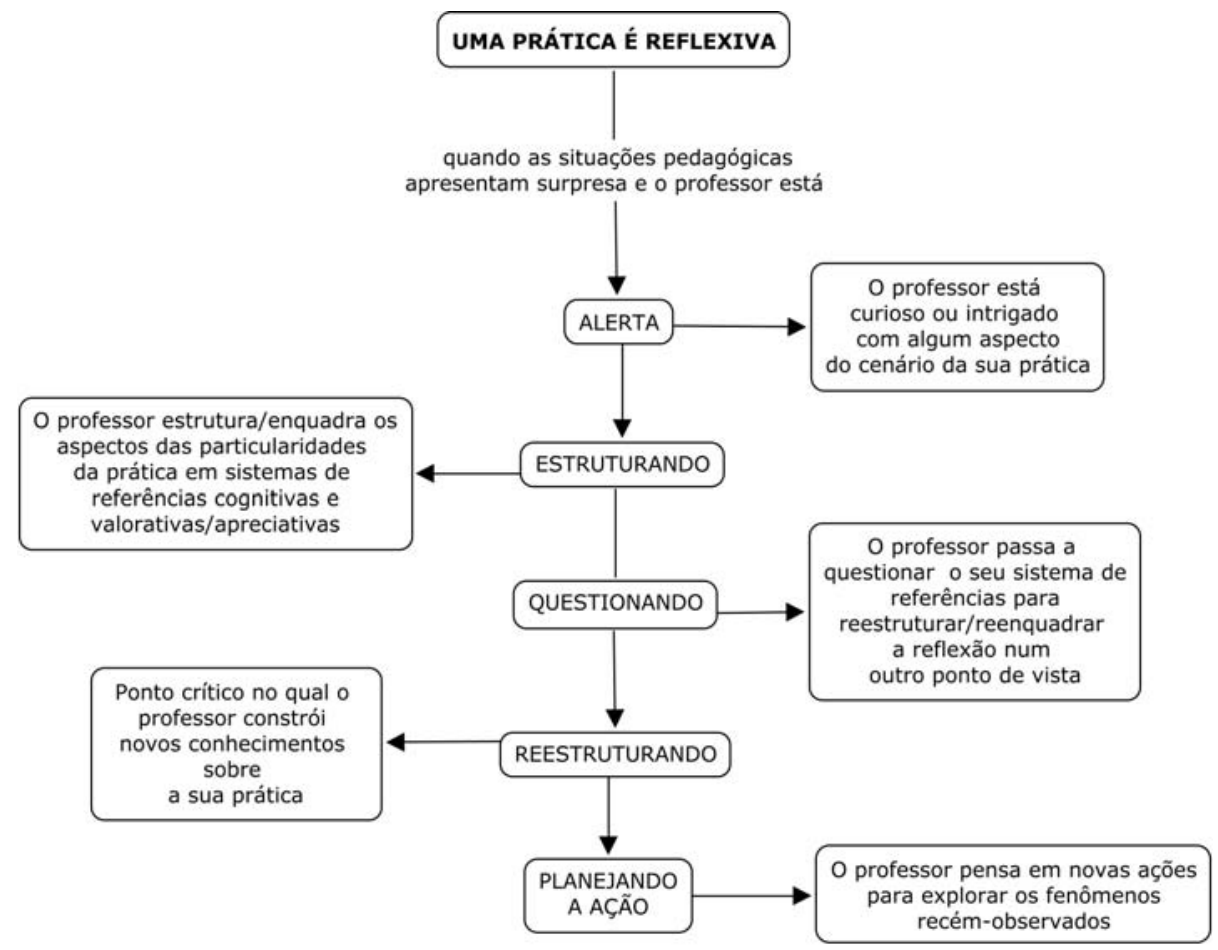

Figura 1 - Esquema simplificado da concepção de prática reflexiva schöniana, adaptado de Clarke (1994, p. 498-499).

Já a reflexão sobre a ação é um processo que não tem qualquer relação com a ação presente e o professor a reconstrói mentalmente com o objetivo de analisá-la retrospectivamente, de modo a descobrir como seu conbecimento na ação pode ter contribuído para um ensino satisfatório ou não. É de natureza lenta e decisão mais controlada, pois ocorre sobre o ensino que de fato já ocorreu.

O terceiro processo, a reflexão sobre a reflexão-na-ação, requer que o professor pense "no que aconteceu, no que observou, no significado que lhe deu e na eventual adoção de outros sentidos. Refletir sobre a reflexão-na-ação é uma ação, uma observação e uma descrição, que exige o uso de palavras" (SCHÖN, 1997, p. 83 - grifo do autor).

O professor, após ter descrito e construído o cenário da sua investigação, poderá criar uma problematização contextualizada, realizar uma análise ou uma avaliação crítica dos aspectos da prática (SCHÖN, 2000). Esse processo de reflexão auxilia o profissional a determinar as ações futuras e a compreender os problemas para solucioná-los (ALARCÃO, 2000). Os esquemas de pensamento criados por esse momento reflexivo podem embasar o que Alarcão (2003) denomina de reflexão para a ação. Trata-se das reflexões que o professor se apoia para sistematizar as atividades de ensino que serão desenvolvidas em sala de aula (ROSA-SILVA; LORENCINI JÚNIOR, 2007). 
No entendimento de Schön, muito do saber do professor equacionase com a capacidade de (re)definir os problemas do dia-a-dia escolar. É uma competência que ou se tem ou se desenvolve, mas que dificilmente se ensina (ALARCÃO, 2000).

Considerando que a prática reflexiva possibilita o desenvolvimento de possíveis mudanças na prática educativa, o presente estudo está delimitado pelas reflexões da professora acerca dos seus alunos, admitindo que as relações interpessoais em sala de aula exercem influências significativas na conduta docente. Os momentos reflexivos com a professora foram problematizados com a ajuda da pesquisadora, a fim de analisar as reflexões que implicaram possíveis mudanças na ação docente.

\section{0 CONTEXTO DA PESQUISA}

A investigação que aqui se descreve ocorreu em uma escola da rede pública estadual localizada no município de Londrina (PR). A professora participante é licenciada em Ciências Biológicas, efetivada em dois concursos na disciplina de Ciências - de $5^{\mathrm{a}}$ a $8^{\mathrm{a}}$ série do ensino fundamental - e tinha 20 anos de magistério no ano da pesquisa (2006). A professora dispunha de quatro horas/atividade ${ }^{1}$ semanais no decorrer do ano letivo de 2006, as quais foram utilizadas para construir a parceria colaborativa entre a pesquisadora e a professora.

No início do nosso contato, a professora nos relatou que os alunos regularmente tinham atitudes que geravam situações conflituosas e impediam o desenrolar das aulas. Diante desse problema, ela se propôs a desenvolver aulas em um enfoque discursivo, por meio de perguntas que propiciassem o desenvolvimento do raciocínio dos alunos. Nesse contexto, o processo de parceria baseou-se em auxiliar a professora nas suas dificuldades, por meio de ações que nos possibilitassem uma reflexão conjunta dos assuntos da sala de aula.

Para auxiliar a construção da parceria, desenvolvemos um procedimento de intervenção reflexiva similar ao que ocorre em uma "sala de espelhos" (SCHÖN, 2000). De acordo com Schön (2000), a "sala de espelhos" é uma estratégia de formação reflexiva que estabelece relações entre uma determinada prática docente e o ensino de sala de aula. Trata-se de uma estratégia na qual o pesquisador apoia-se para auxiliar o professor a problematizar seu trabalho, por meio da demonstração de práticas educativas iguais ou semelhantes às suas. Neste estudo, a estratégia desenvolvida nos moldes de uma "sala de espelhos" foi a autoscopia, por considerarmos que as reflexões sobre a prática da professora decorreram de situações educativas vivenciadas por ela mesma (ROSA-SILVA; LORENCINI JÚNIOR, 2007). Portanto, ao propormos a autoscopia, tivemos a intenção de que a professora refletisse sobre sua ação, tendo como referência sua própria prática. 
A ideia de autoscopia diz respeito a uma ação em que o sujeito voltase sobre si mesmo para analisar-se, com o auxílio de uma tecnologia de imagem de recordação. Sadalla e Larocca (2004) definem autoscopia como videogravação de uma aula que visa à observação, análise e auto-avaliação pelo protagonista dessa aula. As cenas videogravadas são submetidas às sessões de análise após o desenvolvimento da ação, as quais se destinam à apreensão do processo reflexivo do profissional em foco, por meio de suas falas. Interagimos e dialogamos com a professora para estimulá-la a refletir criticamente sobre suas atividades pedagógicas e, assim, compreender seu pensamento docente.

A professora concordou gravar as aulas em vídeo nas séries selecionadas por ela, $5^{\mathrm{a}} \mathrm{C}$ e $7^{\mathrm{a}} \mathrm{B}$, e desde que se sentisse preparada didaticamente para ensinar recorrendo a perguntas em sala de aula. De acordo com essas condições, optamos pela autoscopia trifásica, dividindo-a em três fases propostas por Jackson (apud SAINT-ONGE, 2001) como pré-ativa, interativa e pós-ativa, e adaptando-a conforme as reais necessidades de ensino.

$\mathrm{Na}$ fase pré-ativa realizamos leituras de textos sobre aulas discursivas. Nela, planejamos as atividades de ensino, registrando-as em planos de aulas contendo essencialmente seis elementos: objetivos, conteúdos, estratégias didáticas, recursos de ensino, avaliação e bibliografia. Também ressaltamos o momento de reflexão para a ação proposto por um roteiro norteador de questões com o objetivo de refletir sobre as ações que a professora realizaria em sala de aula.

$\mathrm{Na}$ fase interativa gravamos, em vídeo, cenas das aulas que tivessem como foco central a ação docente, a interação entre a professora e os alunos e algumas ações discentes. Transcrevemos na íntegra a aula videogravada, selecionamos e analisamos cenas que enfatizassem o critério de confronto do que tínhamos discutido na fase pré-ativa para a sessão de discussão na fase seguinte.

$\mathrm{Na}$ fase pós-ativa realizamos uma sessão de discussão, com o auxílio do vídeo, sobre determinadas cenas gravadas da sala de aula. Ressaltamos a reflexão sobre a ação proposta por um roteiro norteador de questões. Esta fase foi gravada em áudio e posteriormente transcrita.

No período da pesquisa foram realizadas oito autoscopias trifásicas. Para a análise e discussão dos dados, utilizamos os da fase pós-ativa. Há três razões que nos levaram a trabalhar com os dados dessa fase. A primeira diz respeito a pouca quantidade de reflexões apresentadas na fase pré-ativa, pois embora tivesse sido uma fase na qual lemos textos e planejamos as aulas, ela não possibilitou um grande número de discussão como na fase pós-ativa. Outra razão refere-se ao fato de a professora alegar que refletia pouquíssimo na fase interativa, caracterizando como expositiva a sua aula. E a última razão tem a ver com o espelhamento que a fase pós-ativa ofereceu. Trata-se de um processo em que a professora refletiu sobre a ação, após ela ter preparado e desenvolvido as aulas, podendo rever as suas condutas, os comportamentos dos alunos, a dinâmica da sala de aula, as interações discursivas, entre outros aspectos ocorridos na fase interativa. Além 
disso, a professora pôde comparar as suas ações com as que foram planejadas na fase pré-ativa.

No processo de intervenção reflexiva, constatamos a recorrência de três dimensões reflexivas da professora, a saber: a dimensão caracterização da prática - quando a professora refletiu sobre o seu ensino; a dimensão emocional quando ela refletiu sobre a sua relação interpessoal em sala de aula, deixando transparecer as suas emoções; e a dimensão discente - quando a professora refletiu sobre os seus alunos. Identificamos a delimitação do início e fim de cada dimensão seguindo a definição de unidade de análise de Danna e Matos (1984), que diz respeito ao conjunto de falas da professora, antecedidas ou não de nossas falas, versando sobre um determinado assunto.

Os dados apresentam-se em ordem cronológica e estão entrecortados por algumas cenas e pelos diálogos entre nós e a professora. Ressaltamos que, embora tenhamos realizado oito autoscopias, as datas dos encontros autoscópicos nem sempre correspondem ao número de encontros realizados, uma vez que a professora referiu-se aos alunos com mais clareza a partir do terceiro encontro da fase pós-ativa.

Como ferramenta analítica para estruturar os dados, utilizamos o conceito de prática reflexiva de Schön $(1997,2000)$. Identificamos, nas reflexões da professora, os estágios de alerta, estruturação, questionamento, reestruturação e plano de ação, os quais são característicos da reflexão na ação; neste estudo, porém, decorreram da reflexão sobre a ação, fase pós-ativa da autoscopia. Uma vez identificado que esses estágios também ocorreram na reflexão sobre a ação, consideramos que eles são passíveis de análises e considerações. Dessa forma, construímos respostas para a seguinte questão: Quais as implicações das reflexões da professora para a sua relação com os alunos?

Este trabalho, de cunho qualitativo e interpretativo, interessa-se mais pelo processo de intervenção reflexiva do que pelo produto dela resultante. As reflexões que a professora atribuiu aos fatos, a ocasiões e a outras pessoas foram de vital importância para a investigação, assim como o contexto educacional de onde emergiram os dados (BOGDAN; BIKLEN, 1994).

\section{APRESENTAC̣ÃO E ANÁLISE DAS REFLEXÕES NA DIMENSÃO DISCENTE}

Vejamos como a professora refletiu sobre a ação em relação aos seus alunos, após observar-se na cena, a seguir, em que instruiu os alunos no dia em que aplicou uma avaliação com consulta.

Professora: É o seguinte, na semana passada eu escrevi aqui no quadro: Trabalho de Ciências entrega dia três do quatro. E o dia três do quatro é hoje.

Esse trabalho vai ser entregue após a prova porque nós vamos fazer três perguntinhas, quatro.

Eu vou entregar as folhas pra vocês e vocês poderão utilizar caderno, livro, o trabalho. Tudo bem!

Quem não fez o trabalho vai fazer a prova do jeito que souber, do jeito que puder e o trabalbo 
infelizmente vem junto com a prova.

Leo: Não tem como fazer (o trabalho) pra entregar depois e receber metade.

Professora: Entregar pela metade da nota. Tipo assim, entregar amanhã valendo 10,0?

Eu não pensei nessa bipótese ainda. Eu não concebi. Sabe por que eu não concebi isso? Porque é o seguinte: o aluno que vai fazer um concurso e chega atrasado pro concurso. Ele deixa entrar.

Aluno: Não.

Professora: Deixa.

Aluno: Pode.

Professora: Vai pra guerra e não leva a arma. Ele volta pra trás e nunca mais vai lutar mais.

Leo: Vai com um batalbão de choque. (Risos).

Professora: Acontece que é o seguinte gente: é na escola que a gente aprende a entregar as coisas no dia certo, na hora certa e do jeito certo, gente! E outra, se a professora aceitar [o trabalbo] depois, como é que vai ficar os [alunos] que fizeram pro dia de hoje?

Leo: Vale 20,0 pontos, wé!

Professora: Valendo mais?

Leo: Ué!

Professora: Posso dá a resposta amanbã?

Alunos: Pode. [...].

(Cena da aula do dia 03/04/06 - Avaliação com consulta)

Professora: $O$ aluno que faz as coisas em casa... Você pode reparar, é um aluno diferente. É um aluno que vai bem, que tem um domínio melhor da situação, ele sabe se situar, ele é diferente. Ele pode conversar, mas ele não atrapalha você com perguntas que não pertencem à aula. [trata-se de perguntas contextualizadas].

Pesquisadora: Quando você disse a função da escola, lembra quais foram as reações deles?

Professora: Eles não falaram nada.

Pesquisadora: Você percebeu o rostinho deles?

Professora: De desânimo para aqueles que não fizeram [o trabalho]. Eu vou dižer uma coisa: a minha frustração é tão grande que mesmo eu dando a oportunidade pra fazer [o trabalbo] no outro dia tem gente que não fez também. O Leo mesmo é um.

Pesquisadora: Que foi quem tentou negociar com você.

Professora: Ele é o que mais me perturba. [...]. Só que ele é um menino que fala, mas ele far: $\mathrm{Na}$ sala de aula ele fa\%. Eu dei [atividade] em grupo, como é que ele fez sentado com as meninas. Tudo bem que as meninas falaram: "ele dá um trabalho danado, ele não sabe onde é que está [o assunto]". No fundo ele demorou. Eu falei: É bom trabalho em grupo pra vocês darem um pouquinho de valor pra aquilo que o professor tem que fazer ao lidar com o grupo inteiro [sala].

Pesquisadora: $O$ Leo é repetente?

Professora: De $6^{a}, 7^{a}$ não. Mas ele é totalmente desarticulado, ele não tem responsabilidade.

(Sessão de discussão do dia 12/04/06)

Nesse trecho, podemos inferir que a professora classifica os alunos em "alunos diferentes" e "alunos comuns". Os estudantes "diferentes" são aqueles que estudam em casa, e em consequência disso, têm memorizado o conteúdo. Esses alunos têm comportamento diferenciado e procuram não se manifestar por meio de perguntas sobre assuntos que possam deixar a professora em situação embaraçosa. Eles realizam as atividades de acordo com o que é solicitado, concordando, provavelmente, com o modo como a professora leciona. Já os alunos "comuns" são os que expressam as suas dúvidas e curiosidades, muitas vezes descontextualizadas. Um exemplo de aluno desse grupo é o Leo: "Ele é o que mais me perturba. / [...] ele é totalmente desarticulado e não tem responsabilidade.” 
Ao apresentarmos mais uma cena sobre avaliação escolar, a professora fez as reflexões abaixo.

Professora: E a quarta questão não está ali [na lousa] porque cada aluno vai formular a questão que gostaria que aparecesse na prova e não apareceu. Quando eu fiz a primeira prova eu fiz um treino. Agora, ela vai fažer parte da avaliação. Então, a quarta questão [...] o aluno vai formular. Então, en vou deixar em branco. Vocês é que vão... Por exemplo, formular questão de desenho, formular de relacione, vocês que vão fazer.

Aluno: Tem que fazer e responder?

Professora: Fazer e responder! Formular a questão e responder.

Hug: Posso fazer... Por que a gente tem que respirar?

Professora: Tem que ser uma pergunta que faça parte de organelas e tecidos! Que faça parte desses dois conteúdos! (Tom reticente).

Wel: $A$, não! O que é tecido?

$[\ldots]$

(Cena da aula do dia 03/04/06 - 7 $\mathrm{B}-$ Avaliação com consulta)

Professora: Ele [o Hug] é um dos que mais captam as coisas e não é de fazer nada. E eu tinha uma concepção errada desse menino. Ele foi meu aluno na $5^{a}$, na $6^{a}$, repetiu a $6^{a}$; fez a $7^{a}$ e repetiu. Eu tinha uma concepção errada, porque ele era muito faltoso, muito relapso, não queria nada com nada. Esse ano ele está organizado e eu não sei o que aconteceu. Ele já era aluno repetente com muito problema, um fracasso escolar propriamente dito, e en fiquei assim: chocada, porque a partir desse momento [de reflexão] a gente vai ter que ter outra postura para avaliar os alunos e analisar. É aí que a escola peca.

Pesquisadora: Qual é o pecado?

Professora: O pecado da avaliação, da reprova. Muitas vezes esse menino não tinha sido estimado nunca.

(Sessão de discussão do dia 12/04/06)

Pela análise da cena e da reflexão feita pela professora, podemos deduzir que o fato de ela pouco esperar dos alunos, que são "um fracasso escolar propriamente dito" na área do conhecimento, influencia no grau de exigência cognitiva da prova. No entanto, a participação do Hug, aluno repetente, faltoso e tido até como relapso, desperta sua atenção. Ela passa a refazer para melhor a imagem que tem do Hug e isso implica voltar à atenção para o aluno e para a maneira como vem avaliando-o.

Continuando as reflexões da professora:

Professora: Aquele aluno que te olha no olho, mesmo fazendo a maior bagunça, mesmo que ele te olhe assim... mas ele está te olhando no olho, esse aluno tem chance de você fazer alguma coisa por ele. Agora, aquele aluno que abaixa a cabeça e não te encara, você tem que tomar cuidado, porque esse aluno é traiçoeiro. Então, você tem que... E é isso que eu não descobri ainda: como fažer esse aluno se inteirar?

(Sessão de discussão do dia 05/05/06)

Nesse fragmento, podemos notar que a professora se deixa influenciar pelo modo como os alunos a olham e disso depende sua iniciativa de aproximar-se deles. O impulso para estabelecer uma relação interpessoal em sala de aula deve partir dos alunos, de sua atenção, de seu procedimento com ela, olhando-a em seus olhos. O aluno tímido ou aquele que por algum motivo faz pouco de sua aula, é 
considerado "traiçoeiro". Pelos excertos analisados anteriormente, podemos inferir que a professora parece demonstrar preconceito contra os alunos. Entretanto, ela faz um questionamento importante: “como fazer esse aluno se inteirar?” Com essa preocupação, ela tenta desenvolver as aulas usando cada vez mais perguntas em sala de aula, para analisar os alunos discursando sobre os assuntos trabalhados.

Ao mostrarmos esta cena, a professora fez relações entre as duas séries que escolheu para experimentar situações diferentes de ensino.

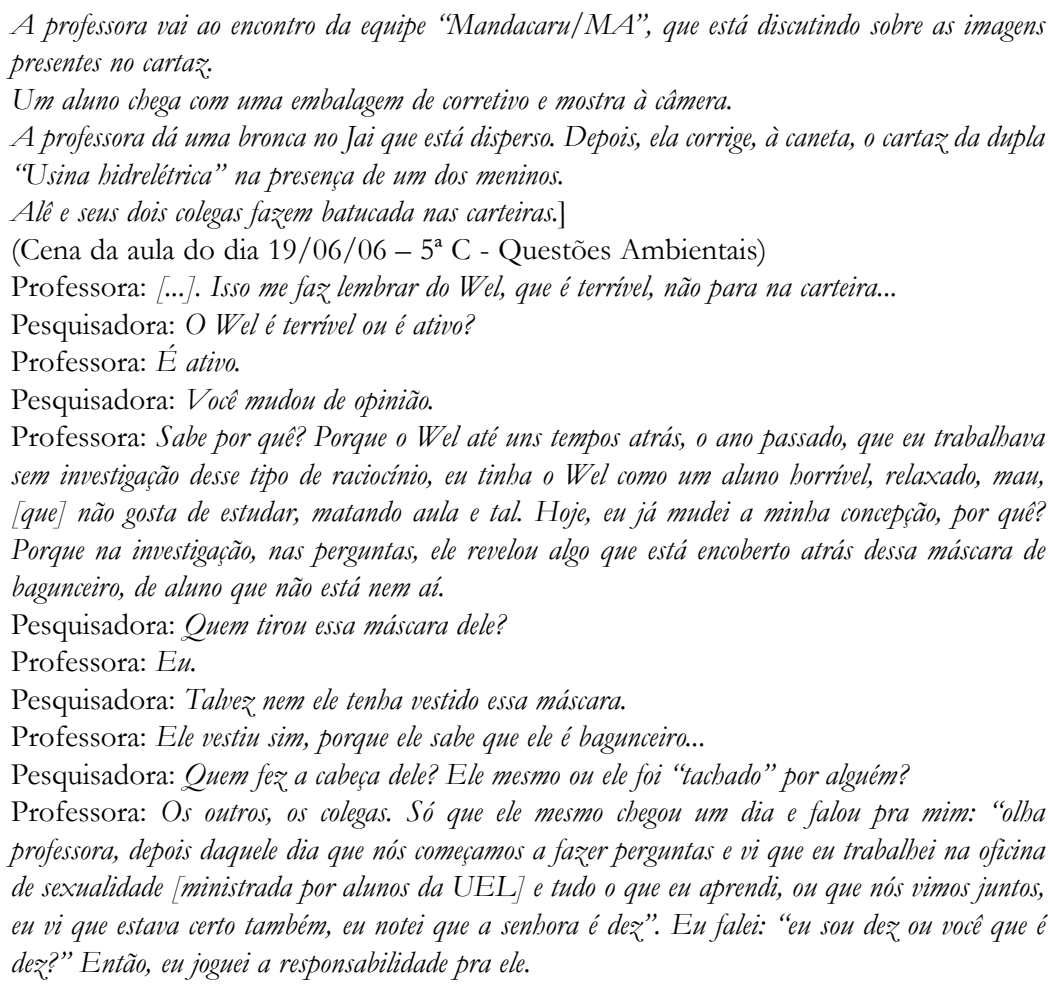

$\mathrm{Na}$ cena que revela um contexto conflituoso ocorrido na $5^{\mathrm{a}} \mathrm{C}$, a professora, ao refletir sobre a ação, lembrou-se do aluno Wel da $7^{\mathrm{a}} \mathrm{B}$. Ao dar liberdade ao aluno para que ele se expresse por meio de perguntas, ela ouve-lhe tentando aproximar-se dele para analisar seu trabalho, para fazer uma avaliação dele. A professora passa a enxergar o estudante Wel com "outros olhos": "de um aluno horrivel, relaxado, mau, [que] não gosta de estudar, matando aula e tal" para o aluno que se expressa oralmente. Desse modo, ela fica atenta ao perfil do estudante para valorizá-lo em aula.

É interessante notar que à medida que a professora evita condutas negativas que poderiam constranger os alunos no momento de eles exporem as suas reflexões nas interações discursivas, o aluno Wel começa a percebê-la de outro modo: "olha, professora, depois daquele dia que nós começamos a fazer perguntas e vi 
que eu trabalhei na oficina de sexualidade [ministrada por alunos da UEL] e tudo o que eu aprendi, ou que nós vimos juntos, eu vi que estava certo também, eu notei que a senhora é dez", pois ele pode relacionar o que estudou em sala de aula com uma situação diferenciada de aprendizagem (oficina de sexualidade promovida pela UEL).

Dando sequência às suas reflexões, a professora pretende estender, para o aluno Jai, a visão positiva que faz do aluno Wel.

Professora: Eu quero chegar a fazer isso na $5^{a} \mathrm{C}$.

Pesquisadora: O quê?

Professora: Com o Jai, principalmente. É o men objetivo. De tirar aquela máscara de que ele é um aluno terrivel. Tudo bem, ele tem defasagem de escrita, de leitura, de oralidade, de um monte de coisas, só que o menino é capaz, alguma coisa ele é capaz de fazer.

Pesquisadora: Como é que você sabe dessa defasagem dele?

Professora: Devido ao como ele escreve na prova. De tudo que ele pergunta. Ou ele está cansado e não quer fazer ou a cabeça dele está bagunçada porque alguém não organižou.

(Sessão de discussão do dia 23/06/06)

Ao referir-se ao aluno Jai, a professora nota que ele tem algumas dificuldades de aprendizagem: "ele tem defasagem de escrita, de leitura, de oralidade, de um monte de coisas", e percebe que ele "é capaz, alguma coisa ele é capaz de fazer".

A professora tem a intenção de livrar-se da impressão negativa que criou contra o Jai - ele é "terrivel" - e ajudá-lo por meio de uma conversa amistosa. Nesse sentido, ela discute conosco sobre o plano de ação, a seguir.

Professora: [...] o Jai é um líder e pode manipular a aula do jeito que ele quiser.

Pesquisadora: Que estratégia você pensa pra resolver esse problema?

Professora: Não adianta ir com autoridade pra cima do Jai.

Pesquisadora: Com autoridade não resolve?

Professora: Com ditadura, com dureza de coração, não adianta. Eu acho que en vou ter que conquistar o Jai, novamente.

Pesquisadora: Por meio de quê?

Professora: De afeto.

Pesquisadora: Que tipo de afeto?

Professora: Não afeto de mãe, porque não vai funcionar isso. Ter uma conversa separada, fora da sala de aula, mas com firmeza, junto com a supervisora, com o diretor e com ele ouvindo. Eu vou ter que chegar e falar assim: Diretor e supervisora, as fitas que nós filmamos, não vão ser passadas pra pai, nem pra psicóloga. Nós chegamos numa grande conclusão: eu estou aqui como amiga do Jai, quero ajudar na postura dele, porque o aluno que mais tumultua, que mais deixa a sala agitada, conflituosa, é o Jai. Então, nós vamos ter que ter uma conversa, não pra repreensão, não estou aqui pra dar suspensão pra ele, porque não é isso que eu quer, só que eu estou aqui pra ajudar ele a amadurecer, porque senão nós não vamos chegar ao fim do ano... E eu vou ter que usar esses argumentos que nós estamos vendo, não pra denegrir. Assim, tipo: não vai passar pra pai, nem pra ninguém, só que o que eu estou observando que as aulas estão sendo tumultuadas devido à postura do Jai, e se ele não vai pra frente alguma consequência vai ter depois. Então, eu já estou alertando, já estou orientando [na conversa]. A supervisora vai falar: "Ah, isso eu já sabia!" Mas, gente, a gente vai ter que agir junto pra tomar uma atitude junto. Vai ter que chamar psicóloga, vai ter que fazer alguma coisa, mas antes de chamar psicóloga e tudo, ele vai ter que ter a consciência disso. Nem que passe essa fita, nesse momento.

(Sessão de discussão do dia 13/07/06) 
Nesse longo trecho, a reflexão sobre a ação possibilita que a professora pense em estratégias que a auxiliaria na reflexão na ação. Ela reconhece que a sua irritabilidade a distancia do aluno. Então reflete sobre uma estratégia para reconquistar o Jai, estudante considerado indisciplinado, pensando em uma conversa amistosa com os gestores da escola, na presença do Jai, expondo a situação conflituosa e incerta que tem enfrentado em sala de aula.

A professora percebe que precisa agir de forma mais afetuosa, auxiliando o aluno a prever as consequências das suas ações em sala e a melhorar a sua conduta, sem reforçar o comportamento negativo dele. Essa conversa teria um caráter disciplinador, caso ela e os gestores tentassem discutir limites ou regras de segurança em sala de aula, já que o Jai comportou-se várias vezes de modo desrespeitoso e com agressividade.

Dando sequência à discussão, perguntamos à professora a respeito do processo de ensino e aprendizagem.

Pesquisadora: Qual é a sua concepção, hoje, de ensino e aprendizagem?

Professora: Eu não sei. Eu não cheguei assim... Eu queria conhecer o cérebro. Eu já falei isso pra você. Eu queria saber quais os recursos que en tenho que utilizar com o Jai, por exemplo. Eu vou pegar o pior exemplo, o mais dificil, mas assim: como fazer pra que ele me ouca? Por exemplo, en vou dar um conselho pra ele. O que en tenho que usar de palavras que são fortes pra uma pessoa dessa? Ou nem palavras.

Pesquisadora: Um dos aspectos num diálogo é o olhar; quando você olha pra pessoa.

Professora: Tudo bem.

Pesquisadora: É conbecimento de contexto, como é que eu posso te explicar: Como é que ele te olha pelo olhar dele? Como você o percebe estando aberto ou não?

Professora: Eu que vou ter que olhar ele [o Jai] diferente. Eu vou ter que tirar os preconceitos que en já criei dele.

Pesquisadora: Você poderia me citar alguns preconceitos?

Professora: Tipo assim: indisciplina. O preconceito de agitado, zombador. Essas palavras nessa conversa, en vou ter que trabalhar isso.

Pesquisadora: Você acha que é isso que está bloqueando?

Professora: Eu acho, de eu pra ele. De eu olhar pra ele com autoritarismo, com raiva como daquelas velhas... Você lembra de "Matilda" [o filme], que a senhora chegava com um chicote... Você nunca assistiu?

(Sessão de discussão do dia 13/07/06)

Nesse processo de reflexão sobre a ação, a professora reconhece que olha para o Jai com desprezo e compara sua conduta irascível com a da atriz do filme "Matilda", que atua como antagonista coagindo a protagonista Matilda. Nessa comparação, a professora constata que a visão que tem do aluno prejudica a sua interação com ele. Ela admite que teria de se livrar da sua aversão em relação ao Jai: "O preconceito de agitado, zombador", para não deixar que isso influencie na conversa amistosa que teria com ele e a equipe de gestão. Podemos afirmar que a professora almeja cultivar uma atitude de "mente aberta" (DEWEY, 1979) em que ela estaria aceitando o aluno e tentando aproximar-se dele.

A seguir, ela comenta sobre o aluno Leo ao observar a cena em que propôs trabalho em grupo para os alunos desenvolverem os conteúdos “Órgãos 
dos Sentidos". Na aula em foco, o grupo de alunos realizou um seminário sobre a "Visão".

Professora: Só uma coisa que en gostaria de lembrar o aluno. É o seguinte: tem aluno que está faltando por demais. Não copiaram as questões. Isso é questão de prova, gente! O final desse trabalho é a prova! Bom! A equipe de hoje é "Visão"!

A professora põe a data na lousa e fala aos meninos: apresenta primeiro para depois...

Quatro alunos se posicionam na frente da sala.

Aluno: Nós somos da equipe da "Visão": eu, Leo, Gui e Bru.

Um dos alunos, Gui, lê a primeira página e meia do trabalho da equipe: "Desde o nas-

cimento, a crianca..." Depois passa a leitura para o aluno da sua esquerda e, assim, sucessivamente.

Tempo da leitura: aproximadamente seis minutos.

Leo lê a pergunta: $O$ que acontece na retina e por quê?

Gui lê a resposta: $A$ imagem é formada invertida em relação ao objeto...

$[\ldots]$

(Cena da aula do dia 24/08/06 - $7^{\mathrm{a}}$ B - Visão)

Professora: Primeira vez que en vejo o Leo quieto. Eu acho que eu analiso ele muito errado, porque ele é um menino que odeia escrever. Aí que o Zabala fala que a gente não precisa avaliar só na escrita. A escrita não é uma nota cem. O Leo tem um raciocinio rápido, muito aprimorado.

Pesquisadora: Como você pode trabalhar a habilidade de raciocinio rápido pra que ele se expresse na escrita?

Professora: Então, o desenho não é uma escrita, né?

Pesquisadora: Não é. O desenho é uma forma de expressão.

Professora: É uma forma de expressão! Como é que eu vou fazer o Leo escrever? Só se eu formular umas perguntas e ele ter que responder!

(Sessão de discussão do dia 02/09/06)

O fato de a professora ter proposto uma atividade em grupo levou o estudante Leo a participar da aula. Nessa ocasião, ela percebe-o quieto e sério o suficiente para dar conta da parte que lhe coube no seminário sobre "Visão". A professora parece reconhecer que tem analisado o Leo de maneira equivocada, ou seja, pela crença de que quanto menos o aluno (re)produz em sala, mais ele é "desinteressado", julgado e culpado pelo seu fracasso escolar.

Apoiada na leitura que fez sobre a obra do autor Zabala (1998), a professora, ao questionar-se "Como é que eu vou fazer o Leo escrever?", busca uma resposta para trabalhar a pouca habilidade redacional do aluno, por meio de perguntas e respostas. Ai que o Zabala fala que a gente não precisa avaliar só na escrita. Ela reconhece que variadas formas de expressão são importantes.

\subsection{Síntese representativa das reflexões de dimensão discente}

Com base nas falas mais significativas da professora de Ciências, apresentamos uma síntese das reflexões da dimensão discente na ordem cronológica em que ocorreram nas sessões de discussão, com o auxílio do vídeo e dos diálogos entre a professora e a pesquisadora, assim como da leitura de alguns textos realizada na fase pré-ativa. Para compreendermos o pensamento da professora, inspiramo-nos no referencial schöniano, propondo uma significação dos estágios reflexivos realizados pela professora, a saber: 
Alerta: a professora, ao observar os alunos no vídeo, detecta o momento da situação educativa em que ocorreu o "chamamento" para refletir sobre o problema. Se por um lado, esse suposto alerta não foi o suficiente para a reflexão na ação que já ocorreu, por outro, consideramos que a reflexão sobre ação possibilitou identificar esse momento e, a partir daí, ela estar atenta às atitudes dos alunos.

Estruturação: a professora classifica os alunos em "comuns e diferentes", revelando, segundo ela, alguns preconceitos contra eles, tais como: "desarticulado, irresponsável, traiçoeiro, terrivel”, dentre outros.

Questionamento: a professora levanta dúvidas a respeito de como agir com determinados alunos, em certas situações. São questionamentos que buscam maneiras de atuar perante os alunos que desencadeiam situações embaraçosas em sala de aula.

Reestruturação: a professora responde aos questionamentos levantados; passa a considerar o aluno ativo no processo de aprendizagem e reconhece que o analisa de forma equivocada, ou seja, constata que o equívoco estava na sua concepção de aluno e não no aluno. A professora dá-se conta de que o pouco desenvolvimento das habilidades cognitivas dos alunos não poderia influenciar nas suas concepções de aluno "bom" ou "ruim". Outro ponto que a ajudou a reestruturar as suas concepções foi o fato de comparar situações que experimentou nas duas séries, que para ela tinham perfis opostos, enquanto a $7^{\mathrm{a}}$ B era "disciplinada", a $5^{\mathrm{a}} \mathrm{C}$, "indisciplinada".

Plano de ação: a professora estabelece estratégias para dissolver os preconceitos que tem contra os alunos.

$\mathrm{Na}$ Figura 2 mostramos que reflexões sobre os alunos foram feitas pela professora de Ciências no processo de reflexão sobre a ação. 


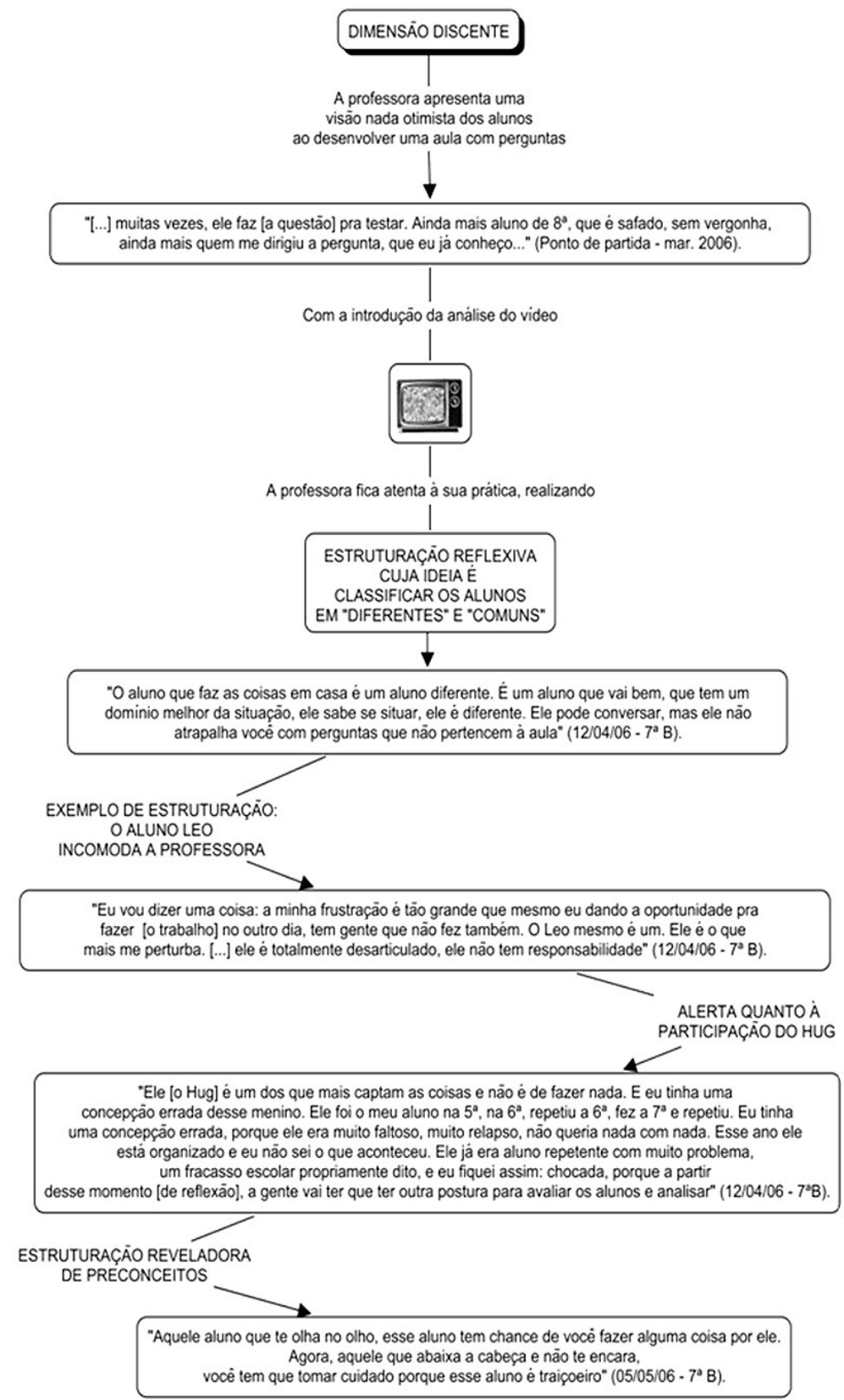




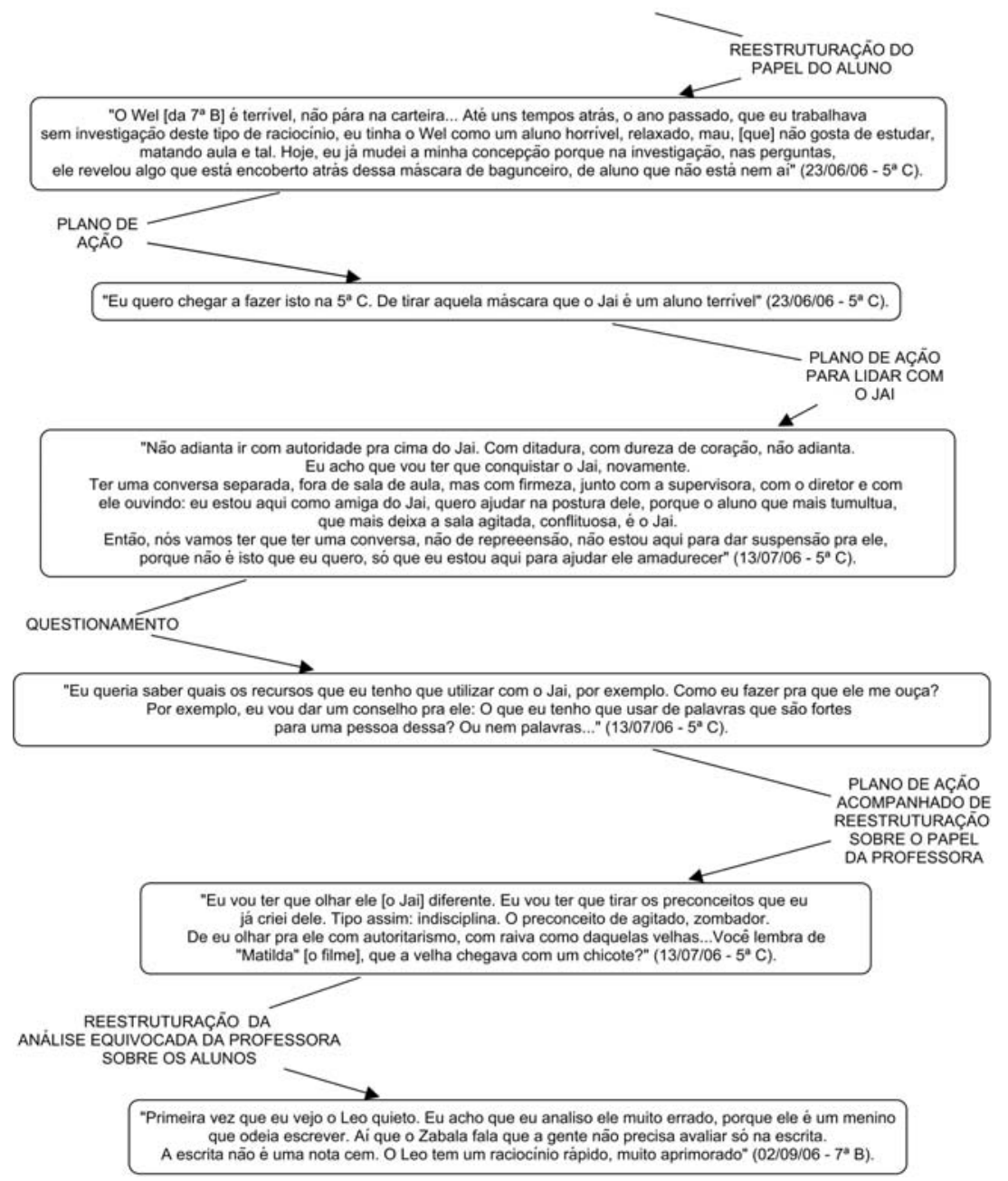

Figura 2 - Esquema das reflexões sobre os alunos da professora de Ciências.

\section{ALGUMAS CONSIDERAC̣ÕES}

Como já relatado anteriormente, a professora teve a intenção de mudar sua prática recorrendo a perguntas que levassem os alunos a desenvolverem o raciocínio e, na tentativa dessa mudança, ela os percebeu em interação discursiva. De acordo com as reflexões, essa percepção acorreu de modo não generalizável para os gêneros masculino e feminino, ou seja, por 
alguma razão, a professora focou a atenção mais nos meninos do que nas meninas, talvez, por terem sido os que mais se expressaram em sala de aula.

As reflexões deixaram transparecer a dinâmica da relação entre a professora e os alunos, cujo enfoque esteve nas impressões negativas criadas contra eles. No caso estudado, a ferramenta analítica dos dados permitiu-nos estruturar o quadro do pensamento docente, com o objetivo de analisar as reflexões sobre as relações interpessoais professora/alunos e suas influências na prática educativa. Pudemos notar que as reflexões feitas inicialmente pela professora revelaram uma desarmonia na relação docente/discente, caracterizada pelo distanciamento entre a professora e os alunos no processo de ensino e aprendizagem. Desconhecemos quando os preconceitos se iniciaram, bem como o tempo que eles perdurariam, pois revelamos dados coletados do processo de formação continuada em médio prazo (um ano letivo).

$\mathrm{O}$ fato de a professora descrever suas condutas; responder a seus questionamentos; realizar análises de confronto entre o que leu e fez em sala; planejar ações, almejando dissolver os preconceitos que criou contra os estudantes, leva-nos a considerar a reflexão sobre a ação, com o auxílio da autoscopia mediada pelos diálogos entre a professora e a pesquisadora, uma estratégia que possibilita a autocrítica do profissional em foco. Desse modo, evita-se que o pesquisador/formador evidencie, por meio de suas falas, as tensões presentes na relação interpessoal entre professor e alunos.

Dewey (1979) afirma que para ocorrer o ensino reflexivo, o professor precisa cultivar a mentalidade aberta, o entusiasmo e a responsabilidade. Neste estudo, consideramos a mentalidade aberta, cujo significado é estar pronto para ouvir o outro, a sustentação da prática reflexiva da professora em que ela interagiria positivamente com os alunos ao desfazer as impressões negativas que criou contra eles.

Do ponto de vista dos procedimentos metodológicos adotados para a investigação, consideramos que a ferramenta utilizada para a análise das reflexões sobre ação mostrou-se profícua na medida em que pudemos identificar e interpretar os estágios reflexivos da fase pós-ativa da autoscopia, bem como identificar a sequência ordenada dos mesmos, os quais constituem o processo dinâmico do pensamento docente. Os movimentos reflexivos entre os estágios de estruturação e reestruturação, que antecedem os planos de ação sustentam as reflexões deste estágio de modo contextualizado, com conteúdo funcional e aplicável em situações educativas. Assim, a ocorrência de planos de ação para a dimensão discente indica significância na prática reflexiva da professora. Consideramos que a professora poderia enquadrar novas situações educativas no que tange a sua relação com os alunos, a fim de construir planos de ação que seriam desenvolvidos em sua prática.

Consideramos, ainda, que a fase pós-ativa da autoscopia possibilita a aprendizagem reflexiva, uma vez que aperfeiçoa a competência docente, a fim de o profissional resolver as situações educativas, estando alerta, estruturando, questionando, reestruturando e planificando ações em sala de aula. 
A utilização do referencial da reflexão na ação para investigar as reflexões sobre a ação na dimensão discente da professora abre caminhos para que os pesquisadores possam ter acesso aos estágios e movimentos reflexivos que ocorrem na fase interativa da autoscopia, isto é, quando o professor efetivamente está desenvolvendo as aulas.

Também consideramos que este trabalho ajuda-nos a compreender parcialmente a formação continuada do professor na escola, pelo fato de se restringir às dificuldades e reflexões de dimensão discente de uma única professora. Acrescentamos ainda, que as dificuldades da prática envolvem outros fatores, tais como os conhecimentos pedagógicos e específicos da matéria a ser ensinada, assim como a relação da professora com a disciplina, consigo mesma e com os outros profissionais na escola. Por fim, recomendamos que pesquisadores atuantes nessa linha de pesquisa desenvolvam e avaliem estratégias coletivas de reflexão na escola. 


\section{NOTA}

${ }^{1}$ A hora/atividade, período em que o professor desempenha funções relacionadas com a docência, que compreende preparação das aulas, processo de avaliação dos alunos, discussões pedagógicas, atendimento à comunidade escolar, atividades de estudo e outras correlatas, será cumprida, integralmente, no mesmo local de exercício e no mesmo turno das horas/aula (PARANÁ, 2003).

\section{REFERÊNCIAS BIBLIOGRÁFICAS}

ALARCÃO, I. Reflexão crítica sobre o pensamento de D. Schön e os programas de formação de professores. In: Formação reflexiva de professores: estratégias de supervisão. Porto: Porto Ed., 2000, p. 9-39.

. Professores reflexivos em uma escola reflexiva. São Paulo: Cortez, 2003.

BOGDAN, R. C; BIKLEN, S. K. Investigação qualitativa em educação. Porto: Porto Ed., 1994.

CANDAU, V. M. Formação continuada de professores: tendências atuais. In: (Org.). Magistério: construção cotidiana. Petrópolis: Vozes, 1997, p. 51-68.

CLARKE, A. Student-teacher reflection: developing and defining a practice that is uniquely one's own. International Journal of Science Education. London: Taylor and Francis, v.1 6, n. 5, p. 497-509, maio 1994. DANNA, M. F. E.; MATOS, M. A. Ensinando observação: uma introdução. São Paulo: EDICON, 1984. DEWEY, J. Como pensamos: como se relaciona o pensamento reflexivo com o processo educativo, uma reexposição. 4 ed. São Paulo: Nacional, 1979.

ELLIOT, J. Recolocando a pesquisa-ação em seu lugar original e próprio. In: GERALDI, Corinta Maria G. et al. (Orgs.). Cartografias do trabalho docente. Campinas, SP: Mercado das Letras, 1998, p. 137-152. LORENCINI JÚNIOR, Á. As demandas formativas do professor de ciências. In: CAINELLI, M. R.; SILVA, I. F. (Orgs). O estágio na licenciatura: a formação de professores e a experiência interdisciplinar na Universidade Estadual de Londrina. Londrina: EDUEL, 2009, p. 21-42.

NÓVOA, A. O professor pesquisador e reflexivo. 2001. Disponível em:

<http://www.redebrasil.tv.br/salto/entrevistas/antonio_novoa.htm>. Acesso em: 15 jul. 2008.

PARANÁ (Estado). Secretaria da Educação. Resolução n. 10/2003. Dá nova redação à Resolução n. 06/2003, que trata da regulamentação de distribuição de aulas. Disponível em:

<http://www.diaadiaeducacao.com.br/portals/portal/institucional/def/pdf/def_ef_resol1003.pdf> Acesso em: 12 maio 2005.

ROSA-SILVA, P. O.; LORENCINI JÚNIOR, Á. Análise das reflexões de uma professora de Ciências do Ensino Fundamental sobre Avaliação Escolar. Estudos em Avaliação Educacional. São Paulo, v. 18, n. 38, p. 111-136, set-dez, 2007.

. Superando conflitos na construção de uma pesquisa colaborativa na escola. Ensaio: pesquisa em educação em ciências, Belo Horizonte, v. 9, n. 2, p. 220-236, dez. 2007.

SADALLA, A. M. F. A.; LAROCCA, P. Autoscopia: um procedimento de pesquisa e de formação. Educação e Pesquisa, 2004. Disponível em: <http://www.scielo.br/scielo.pdf> Acesso em: 26 mar. 2006. SAINT-ONGE, M. O ensino na escola: o que é, como se faz. 2 ed. São Paulo: Loyola, 2001.

SCHÖN, D. A. Formar professores como profissionais reflexivos. In: NÓVOA, António. (Coord.). Os professores e a sua formação. 3.ed. Lisboa: Dom Quixote, 1997. p. 77-91.

. Educando o profissional reflexivo: um novo design para o ensino e a aprendizagem. Porto Alegre: Artes Médicas Sul, 2000.

ZABALA, A. A prática educativa: como ensinar. Porto Alegre: ArtMed, 1998.

Data de recebimento: 29/10/08

Data de aprovação: 24/08/09

Data de versão final: 13/10/09 